\title{
GENOTIPAGEM DO GENE KAPPA CASEÍNA E SUA INFLUÊNCIA NA PORCENTAGEM DE CASEÍNA E PRODUÇÃO DE QUEIJO FRESCAL
}

Andressa Bianca Silva Veronezi, Luciana Machado Guaberto, Diana Silva Araujo, Telma Reginato Martins.

Universidade do Oeste Paulista - UNOESTE, Curso de Farmácia e Bioquímica, Presidente Prudente, SP. e-mail: andressaveronezi19@hotmail.com

\section{RESUMO}

O Brasil é o quarto maior produtor de leite do mundo e a biologia molecular permite genotipar o rebanho dos pecuaristas visando maior produtividade e rendimento de teores de proteínas. $O$ objetivo do presente estudo foi genotipar o gene K-CN em 18 vacas do rebanho leiteiro das raças Holandesa, Girolando e Mestiços, utilizando a técnica PCR- RFLP, e comparar com o rendimento de queijo frescal. Os resultados mostraram que o genótipo $A B$ apresentou maior influência no rendimento de queijo frescal entre as três raças estudadas $(p=0,01)$. Esses resultados indicam que as variações genéticas para $K-C N$ podem ser usadas para aplicação da seleção assistida por marcadores visando à produção de queijo frescal para os animais da raça Holandesa, Girolando e as vacas sem raça definida.

Palavras-chave: caseína, genotipagem, k-CN, PCR-RFLP, queijo frescal.

\section{GENOTYPING OF KAPPA CASEIN GENE AND ITS INFLUENCE ON THE PERCENTAGE OF CASEIN AND PRODUCTION OF UNRIPENED CHEESE}

\begin{abstract}
Brazil is the world's fourth largest milk producer and the molecular biology allows the genotyping of cattle ranchers seeking greater productivity and yield of protein levels. The aim was to genotype the $\mathrm{K}-\mathrm{CN}$ gene in 18 cows in the dairy herd of Holstein, Gir and Mestizos by PCR, and compare the performance of unripened cheese. The results showed that the $A B$ showed higher influence on the yield of unripened cheese among the three breeds studied $(\mathrm{p}=0.01)$. These results indicate that the genetic variations for $\mathrm{K}-\mathrm{CN}$ can be used for the application of marker assisted selection aimed at producing unripened cheese for the animals of Holstein, Gir and crossbred cows.
\end{abstract}

Keywords: casein, genotyping, k-CN, PCR -RFLP, unripened cheese.

\section{INTRODUÇÃO}

O Brasil é o quarto produtor mundial de leite de vaca, ficando atrás apenas de EUA, Índia e China. O leite está entre os produtos mais importantes da agropecuária nacional, superado apenas por café e arroz ${ }^{1,2}$. Em 2010 o Ministério da agricultura calculou que a taxa anual de produção em 2020 terá um aumento de 1,95\% enquanto o consumo será de $1,98 \%$ e a exportação de $5,78 \%^{3}$. A qualidade e a produção do leite de vaca são influenciadas por fatores ambientais como a nutrição, fatores genéticos como raça e a fisiologia conforme a idade ao primeiro parto, período de lactação e ordem de parto ${ }^{4}$.
As proteínas presentes no leite são divididas em dois grandes grupos: as caseínas e as proteínas do soro ${ }^{5}$. Há quatro tipos de caseínas: $\alpha 1, \alpha 2, \beta$ e K. A caseína $\alpha 1$ compreende entre 39 a $46 \%$ do total das proteínas ${ }^{6}$. A Kappa caseína constitui cerca de $25 \%$ da fração de caseína do leite e vários polimorfismos foram encontrados para esta proteína ${ }^{7}$.

A elaboração de queijo é a principal atividade na indústria de laticínios, especialmente nas regiões Sul e Sudeste do Brasil ${ }^{8}$. Lima ${ }^{9}$, ao avaliar o polimorfismo do gene $\mathrm{O} \mathrm{K}-\mathrm{CN}$ codificador da Kappa caseína, verificou maior frequência do alelo $A$ em relação ao $B$. $O$ alelo $B$ segundo a literatura está associado com o aumento da proteína no leite, bem como a 
produção de queijo, com propriedades de coagulação superiores para produção de queijo ${ }^{10}$. E promove um aumento na produção de queijo e melhora a qualidade do queijo alem de estar relacionado com outros valiosos parâmetros de produtividade de leite e composição química de leite ${ }^{11}$.

A biologia molecular traz novas ferramentas nos processos de melhoramento animal $o$ que, aliadas às metodologias tradicionais, contribuem para o progresso genético dos animais domésticos ${ }^{7}$. 0 polimorfismo genético com relação às proteínas lácteas, em particular a kappa-caseína ( $\mathrm{K}-\mathrm{CN}$ ) e a beta-lactoglobulina ( $\beta-\mathrm{LG})$, tem sido associado às diferenças na composição, características de processamento e qualidade do leite, além de parâmetros de produtividade ${ }^{12}$.

O objetivo deste estudo foi genotipar as fêmeas em idade reprodutiva do rebanho leiteiro com 18 animais em idade reprodutiva sendo 6 vacas da raça Holandês, intituladas de grupo $H, 6$ vacas da raça Girolando referente ao grupo $\mathrm{G}$ e 6 vacas de raça Mestiça, que fazem parte do grupo $S$ da fazenda experimental da UNOESTE, através da técnica de PCR quanto ao gene K-CN e comparar os genótipos com os parâmetros físicoquímicos do extrato seco e rendimento em caseína na produção de queijo frescal nas respectivas amostras de leite.

\section{METODOLOGIA}

A presente pesquisa foi realizada com 18 animais em idade reprodutiva sendo 6 vacas da raça Holandês, intituladas de grupo $\mathrm{H}, 6$ vacas da raça Girolando referente ao grupo $\mathrm{G}$ e 6 vacas de raça Mestiça, que fazem parte do grupo $S$ (aprovado pela CEUA da Unoeste, protocolo $n$. 2435). Foram coletados $5 \mathrm{~mL}$ de sangue venoso de cada animal, em tubos a vácuo contendo EDTA e o volume de um litro de leite em recipiente limpo de plástico, por ordenha manual, as análises descritas abaixo foram realizadas em triplicata.

A identificação do gene O DNA genômico foi extraído a partir do sangue de acordo com a técnica de lodeto de sódio ${ }^{13}$. E posteriormente submetidas à reação da cadeia polimerase (PCR) em termociclador (Labnet, Biosystems). Para o gene da K-CN, os "primers" utilizados foram o BKC1: 5' ATCATTTATGGGCCATTCCACCAAAG 3' e o BCK3: 5' TTAGCCCATTTCGCTTCTCTGTAACA 3' para a amplificação de um fragmento de 350pb. A solução de reação conteve 100ng de DNA, 10\% de tampão para PCR (20 mM Tris- $\mathrm{HCl}, \mathrm{pH} 8,4$, $50 \mathrm{mM} \mathrm{KCl}), 1,5 \mathrm{mM} \mathrm{MgCl}_{2}, 0,2 \mu \mathrm{M}$ de DNTP, $0,4 \mu \mathrm{M}$ de cada "primer" e 1 U de Taq DNA polimerase, totalizando $25 \mu \mathrm{L}$. As reações para o gene da K-CN ocorreram em 44 ciclos e as temperaturas empregadas foram: desnaturação a $95^{\circ} \mathrm{C}$ por 1 minuto; anelamento a $52^{\circ} \mathrm{C}$ por 1 minuto; extensão a $72^{\circ} \mathrm{C}$ por 1 minuto e 30 segundos; e extensão final a $72^{\circ} \mathrm{C}$ por 4 minutos $^{14}$.

O produto da amplificação sofreu digestão pela enzima $\operatorname{Hinf} I$, nas seguintes condições: $10 \mu \mathrm{L}$ do produto do PCR, 1,25 U da enzima, $10 \%$ do tampão de reação e água mili-Q totalizando $13 \mu \mathrm{L}$, que foi incubado por três horas a $37^{\circ} \mathrm{C}$, conforme método adaptado por Regitano e Coutinho ${ }^{15}$. Após a digestão enzimática, $13 \mu \mathrm{L}$ as amostras foram submetidas à corrida de eletroforese a 100 volts por duas horas em gel de agarose a $2 \%$ corado com $2 \mu \mathrm{L}$ de Brometo de Etídio $(10 \mathrm{mg} / \mathrm{mL})$. Para a visualização das amostras em gel, utilizamos o corante azul de Bromofenol $(0,01 \%)$. O resultado foi observado com iluminação ultravioleta em câmara escura e as imagens capturadas por uma câmera CCD Alpha-Innotech, utilizando-se o software Quantum Capt.

Para a determinação de caseína, foram utilizados $40 \mathrm{~mL}$ de água a $50^{\circ} \mathrm{C}$ e $1 \mathrm{ml}$ de solução saturada de sulfato duplo de alumínio e potássio seguido de agitação. $O$ material foi filtrado em papel de filtro e lavado com $50 \mathrm{~mL}$ de água. $\mathrm{O}$ papel de filtro com o resíduo foi transferido para um tubo de (fator 6,38$)^{16}$.

Para calcular o rendimento do queijo minas frescal foram pesados 300 gramas do leite a $35^{\circ} \mathrm{C}$, foram acrescentados cloreto de cálcio $(25 \% / \mathrm{L})$, iogurte natural $(10 \mathrm{~g} / \mathrm{L})$ e coalho (1 $\mathrm{mL} / \mathrm{L}$ ). Após descanso de 50 minutos, a massa formada foi cortada. Os queijos enformados foram pesados após 12 horas. A determinação prévia do extrato seco total dos queijos em estufa a $105^{\circ} \mathrm{C}$ até peso constante ${ }^{16}$. O rendimento das fabricações dos queijos foi expresso em gramas de sólidos totais de queijo por litro de leite (g ST/I) e calculados através da fórmula:

$$
\mathrm{R}(\mathrm{gST} / \mathrm{L})=\frac{\mathrm{P} \times \mathrm{ST} \times 10}{\mathrm{~V}}
$$

Onde: $\mathrm{R}=$ rendimento; $\mathrm{P}=$ quilo de queijo obtido; $\mathrm{ST}=$ porcentagem de extrato seco dos queijos; $\mathrm{V}$ $=$ volume de leite utilizado ${ }^{16}$. 
A Análise estatística para verificar as diferenças entre os parâmetros analisados e a interferência da genotipagem, foi realizada a Análise de Variância (ANOVA) dos dados e para a comparação de médias o teste de Tukey, em nível de significância de $1 \%(\mathrm{p}<0,01)$, utilizando-se 0 software BioEstat 5.0.

\section{RESULTADOS}

As frequências genotípicas foram estimadas por contagem simples dos genótipos visualizados na eletroforese obtida com o uso da técnica de PCR- RFLP (Figuras 1 e 2 ) e os padrões de migração se repetiram evidenciando a detecção do polimorfismo. Por meio da técnica de PCR foi possível a amplificação de um seguimento do gene $\mathrm{K}-\mathrm{CN}$ com $350 \mathrm{pb}$, correspondente aos "primers" desenhados e com resultados da literatura para o gene em questão (Figura 1).

Após a amplificação do gene K-CN, foi realizado o tratamento de digestão com a enzima Hinf $\mathrm{I}$, e identificado dois sítios de restrição no produto de amplificação do gene da Kappa Caseína para o alelo A; posição $134 \mathrm{pb}$ e outro na posição $266 \mathrm{pb}$; no entanto o alelo $B$ apenas no último sítio foi detectado, o que corresponde aos relatos de Medrano Aguilar-Cordova ${ }^{14}$ A digestão do alelo A produz bandas com $84 \mathrm{pb}$ e $132 / 134 \mathrm{pb}$, e $O$ alelo $B$ resulta em fragmentos de restrição com $84 \mathrm{pb}$ e $266 \mathrm{pb}$, o alelo $A B$ resulta em fragmentos de restrição com $84 \mathrm{pb}, 132 / 134 \mathrm{pb} /$ $266 \mathrm{pb}$ como pode ser observado na Figura 2.

M 1H 2H 3H 4H 5H 6H 1G 2G 3G 4G 5G 6G 1S 2S 3S 4S 5 S $6 S$

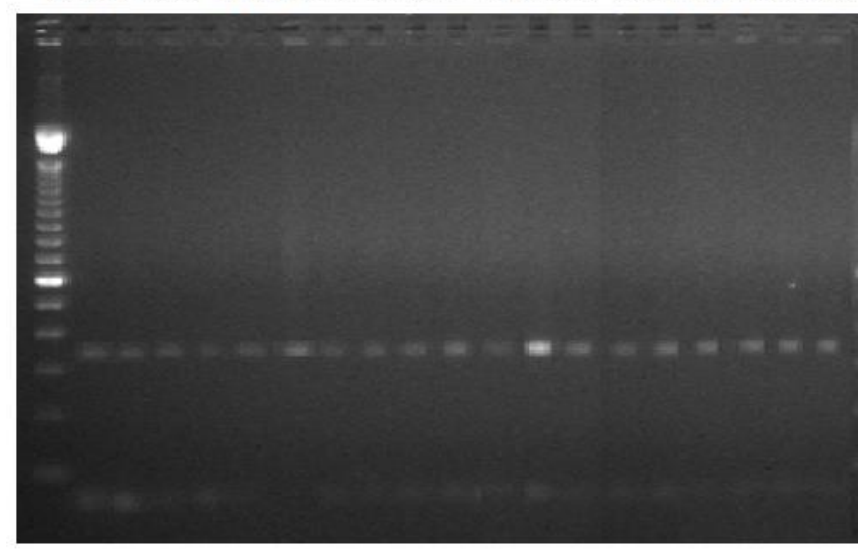

Figura 1. Produto de amplificação do gene Kappa caseína com $350 \mathrm{pb}$ em gel de agarose 1,5\%. Marcador molecular 100 pb (INVITROGEN). Linha 1H, 2H, 3H, 4H, 5H, 1G, 3G, 3G, 1S, 2S, 3S - AA; linha 6H, 2G, 5G, 6G, $4 S, 5 S, 6 S-A B$; $B$ controle negativo. Linha $1 \mathrm{H}$ a $6 \mathrm{H}$ - grupo $\mathrm{H}$ (animais da raça Holandesa); linha $1 \mathrm{G}$ a $6 \mathrm{G}-$ grupo $G$ (animais da raça Girolando); linha $1 S$ a $6 S$ - grupo $S$ (animais se identificação de raça).

Nossos resultados demonstraram que 11 amostras apresentaram 0 genótipo $A A, 7$ apresentaram $O$ genótipo $A B$ e nenhuma apresentou o genótipo BB.

De acordo com os resultados contidos na Tabela 1, os teores de extrato seco não obtiveram diferença significativa entre os 6 animais do mesmo grupo. A média do grupo foi de 10,37\%, a Tabela 2 mostra uma média de extrato seco de $10,92 \%$ e a Tabela 3, 9,27\%. Admite-se no leite normal um mínimo de $11,41 \%$ de extrato seco total ${ }^{17}$. 


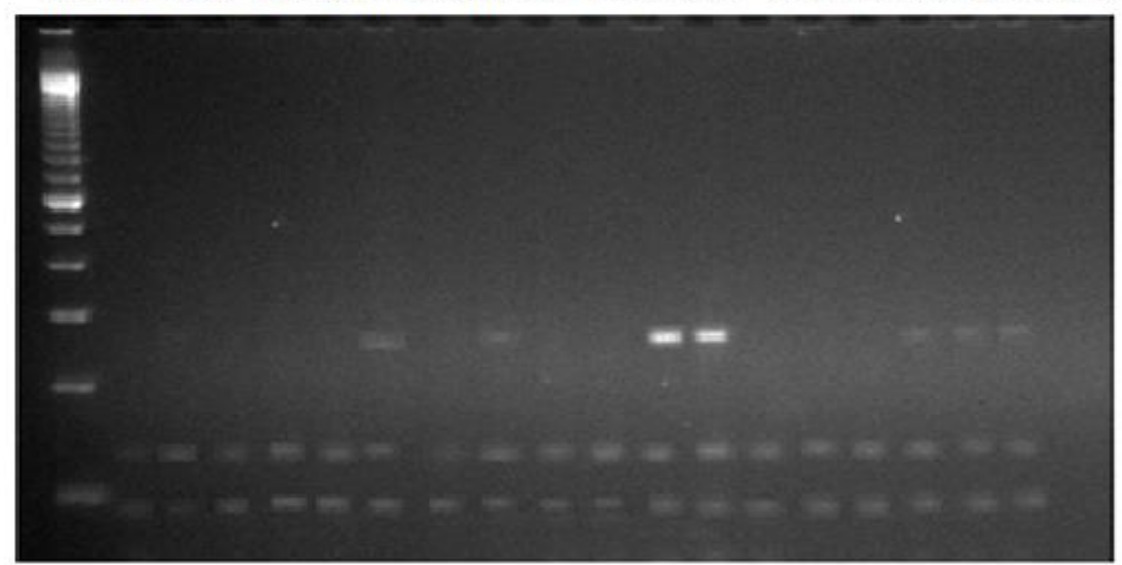

Figura 2. Gel agarose 2,5\% para o gene K-CN: linha 1 - Marcador Molecular 100pb; linha $1 \mathrm{H}, 2 \mathrm{H}, 3 \mathrm{H}, 4 \mathrm{H}, 5 \mathrm{H}$, $1 G, 3 G, 3 G, 1 S, 2 S, 3 S-A A$; linha $6 H, 2 G, 5 G, 6 G, 4 S, 5 S, 6 S-A B ; B$ controle negativo. Linha $1 \mathrm{H}$ a $6 \mathrm{H}$ - grupo $\mathrm{H}$ (animais da raça Holandesa); linha $1 \mathrm{G}$ a 6G - grupo G (animais da raça Girolando); linha $1 \mathrm{~S}$ a 6S - grupo S (animais Mestiços).

Tabela 1. Grupo H (animais da raça Holandesa) teores de extrato seco (g.100g ${ }^{-1}$ ), proteínas (g.100g ${ }^{-1}$ ), rendimento de queijo minas frescal e genotipagem do gene Kappa caseína.

\begin{tabular}{cccccc}
\hline Amostra & $\begin{array}{c}\text { Teores de extrato } \\
\text { seco }\left(\mathbf{g} \cdot \mathbf{1 0 0 \mathbf { g } ^ { - 1 } )}\right.\end{array}$ & $\begin{array}{c}\text { Caseína } \\
\left(\mathbf{g} \cdot \mathbf{1 0 0 \mathbf { g } ^ { - 1 }}\right)\end{array}$ & $\begin{array}{c}\text { Rendimento de } \\
\text { queijo minas } \\
\text { frescal (gst. } \mathbf{~ I}^{-1} \text { ) }\end{array}$ & $\begin{array}{c}\text { Genotipagem } \\
\text { do gene } \\
\text { kappa caseína }\end{array}$ \\
\hline Grupo H & 1 & $10,5 \pm 0,8 \mathrm{ab}^{*}$ & $2,6 \pm 0,09 \mathrm{a}$ & $3,0 \pm 0,13 \mathrm{a}$ & $\mathrm{AA}$ \\
& 2 & $9,38 \pm 0,04 \mathrm{a}$ & $2,3 \pm 0,3 \mathrm{a}$ & $2,9 \pm 0,02 \mathrm{ac}$ & $\mathrm{AA}$ \\
& 3 & $11,85 \pm 0,1 \mathrm{c}$ & $2,1 \pm 0,03 \mathrm{a}$ & $6,9 \pm 1,01 \mathrm{~b}$ & $\mathrm{AA}$ \\
& 4 & $9,6 \pm 0,2 \mathrm{a}$ & $2,3 \pm 0,5 \mathrm{a}$ & $2,8 \pm 0,09 \mathrm{ac}$ & $\mathrm{AA}$ \\
& 5 & $9,8 \pm 0,03 \mathrm{a}$ & $2,2 \pm 0,04 \mathrm{a}$ & $2,0 \pm 0,08 \mathrm{ad}$ & $\mathrm{AA}$ \\
\hline
\end{tabular}

* Letras diferentes na mesma coluna apresentam diferença significativa $(p<0,01)$ pelo teste de Tukey.

Tabela 2. Grupo $G$ (animais da raça Girolando) teores de extrato seco (g.100g-1 ), proteínas (g.100g-1), rendimento de queijo minas frescal e genotipagem do gene Kappa caseína.

\begin{tabular}{cccccc}
\hline Amostra & $\begin{array}{c}\text { Teores de extrato } \\
\text { seco }\left(\mathbf{g} \cdot \mathbf{1 0 0 \mathbf { g } ^ { - 1 } )}\right.\end{array}$ & $\begin{array}{c}\text { Caseína } \\
\left(\mathbf{g} \cdot \mathbf{1 0 0 \mathbf { g } ^ { - 1 } )}\right.\end{array}$ & $\begin{array}{c}\text { Rendimento de } \\
\text { queijo minas } \\
\text { frescal (gST. } \mathbf{~ I}^{-1} \text { ) }\end{array}$ & $\begin{array}{c}\text { Genotipagem } \\
\text { do gene } \\
\text { kappa caseína }\end{array}$ \\
\hline & 7 & $9,3 \pm 0,04 \mathrm{ab}$ & $2,3 \pm 0,03 \mathrm{a}$ & $1,7 \pm 0,1 \mathrm{ac}$ & $\mathrm{AA}$ \\
Grupo G & 8 & $11,6 \pm 0,2 \mathrm{a}$ & $2,4 \pm 0,1 \mathrm{a}$ & $6,6 \pm 0,9 \mathrm{~b}$ & $\mathrm{AA}$ \\
& 9 & $10,3 \pm 0,08 \mathrm{ab}$ & $2,6 \pm 0,005 \mathrm{a}$ & $4,6 \pm 0,07 \mathrm{ad}$ & $\mathrm{AA}$ \\
& 10 & $9,6 \pm 0,1 \mathrm{bc}$ & $2,0 \pm 0,1 \mathrm{a}$ & $6,5 \pm 0,8 \mathrm{~b}$ & $\mathrm{AB}$ \\
& 11 & $14,5 \pm 0,1 \mathrm{~d}$ & $2,8 \pm 0,06 \mathrm{ac}$ & $14,7 \pm 0,8 \mathrm{e}$ & $\mathrm{AB}$ \\
\hline
\end{tabular}

* Letras diferentes na mesma coluna representam diferença significativa $(p<0,01)$ pelo teste de Tukey. 
Tabela 3. Grupo S (animais sem raça definida) teores de extrato seco $\left(\mathrm{g} .100 \mathrm{~g}^{-1}\right)$, proteínas $\left(\mathrm{g} .100 \mathrm{~g}^{-1}\right)$, rendimento de queijo minas frescal e genotipagem do gene Kappa caseína.

\begin{tabular}{cccccc}
\hline Amostra & $\begin{array}{c}\text { Teores de extrato } \\
\text { seco }\left(\mathbf{g} \cdot \mathbf{1 0 0 g}^{-1}\right)\end{array}$ & $\begin{array}{c}\text { Caseína } \\
\text { (g.100 }^{-1} \text { ) }\end{array}$ & $\begin{array}{c}\text { Rendimento de } \\
\text { queijo minas } \\
\text { frescal (gst. } \text { I }^{-1} \text { ) }\end{array}$ & $\begin{array}{c}\text { Genotipagem } \\
\text { do gene kappa } \\
\text { caseína }\end{array}$ \\
\hline \multirow{3}{*}{ Grupo $\mathrm{S}$} & 13 & $9,3 \pm 0,05 \mathrm{a}$ & $2,3 \pm 0,5 \mathrm{~b}$ & $1,1 \pm 0,04 \mathrm{a}$ & $\mathrm{AA}$ \\
& 14 & $8,7 \pm 0,2 \mathrm{a}$ & $2,2 \pm 0,06 \mathrm{~b}$ & $2,0 \pm 0,02 \mathrm{~b}$ & $\mathrm{AA}$ \\
& 15 & $9,6 \pm 0,08 \mathrm{~b}$ & $2,2 \pm 0,04 \mathrm{~b}$ & $4,9 \pm 0,2 \mathrm{c}$ & $\mathrm{AA}$ \\
& 16 & $8,6 \pm 0,05 \mathrm{a}$ & $1,9 \pm 0,5 \mathrm{a}$ & $1,3 \pm 0,06 \mathrm{ab}$ & $\mathrm{AA}$ \\
& 17 & $11,2 \pm 0,2 \mathrm{c}$ & $2,4 \pm 0,04 \mathrm{~b}$ & $6,6 \pm 0,9 \mathrm{~d}$ & $\mathrm{AB}$ \\
& 18 & $8,2 \pm 0,9 \mathrm{a}$ & $2,1 \pm 0,1 \mathrm{~b}$ & $6,5 \pm 0,8 \mathrm{~d}$ & $\mathrm{AB}$ \\
\hline
\end{tabular}

* Letras diferentes na mesma coluna representam diferença significativa $(p<0,01)$ pelo teste de Tukey.

A caseína foi o parâmetro seguinte a ser analisada, no grupo $\mathrm{H}$ a média entre os animais de genótipo AA tiveram $23 \%$ assim como o animal com genótipo AB. A média estimada é de $25 \%{ }^{16}$. Os demais grupos apresentaram mesmo perfil entre as amostras.

Em relação ao rendimento de queijo frescal relacionado ao genótipo AB na Tabela 1, a amostra 6 teve seis vezes mais rendimento em relação ao genótipo AA. Na Tabela 2 do grupo $G$ os animais com genótipos $A B$ foram três vezes superiores em relação aos genotipados $A A$. $O$ grupo $S$ representado na Tabela 3 demonstrou que os animais $A B$ foram três vezes mais produtivos em termos de rendimento de queijo quando comparados aos animais AA.

De modo geral o grupo $\mathrm{H}$ apresentou maior rendimento do queijo frescal com $25,1 \%$. O grupo $\mathrm{S}$ foi o que menos teve rendimento com apenas $8,74 \%$.

\section{DISCUSSÃO}

Deb et al. ${ }^{19}$, pesquisou o polimorfismo da kappa caseína em 200 animais e observou que o alelo $A$ foi mais frequente do que o alelo $B$ entre a população de Frieswal. Curiosamente nenhum BB foi observado entre o homozigoto na população estudada, assim como o presente trabalho. Os referidos autores notaram que os animais com alelos $A B$ tiveram um maior rendimento de leite total no período de 300 dias quando comparados aos do genótipo AA. Oner e Elmaci ${ }^{20}$ relacionou um maior rendimento de queijos nos genótipos k-caseína (BB), $\beta$-caseína $\left(A^{2} A^{2}\right)$ e $\beta$-lactoglobulina (AA). Dentre os animais avaliados não foi possível detectar o alelo homozigoto $\mathrm{BB}$, ao contrario do encontrado por Jairam e Nair ${ }^{21}$ e Ng-Kwai-Hang ${ }^{22}$ que observaram superior produção leiteira para as vacas holandesas com o genótipo BB.

Animais BB apresentam rendimento $12 \%$ superior de caseína encontrada no fabrico do queijo muçarela e $8 \%$ de no fabrico do queijo tipo cheddar em relação aos animais com o genótipo $A A$. Os animais $A B$ apresentam rendimento intermediário entre os genótipos $B B$ e $A A$. Animais AA possuem o genótipo menos favorável para produção de queijo'. Stipp et al. $^{12}$, ao analisar a frequência genotípica $A A, A B$ e $B B$, por meio das mesmas técnicas descritas neste trabalho, associando com a produção de leite $(\mathrm{kg}$ leite/dia) em bovinos das raças Girolanda, Holandesa e Jersey, concluiu que o alelo B da K$\mathrm{CN}$ apresentou maior produtividade leiteira nas raças Girolanda e Holandesa.

$\mathrm{A}$ alta peridiocidade do alelo $\mathrm{A}$ do gene da k-CN na raça Girolanda possivelmente está relacionada à sua origem em cruzamentos das raças Gir e Holandesa. Estudos de Van der Berg et al. ${ }^{10}$ encontraram alta frequência do alelo $B$ na raça Jersey e afirmaram que a presença desse alelo contribui com 8 a 10\% na composição de proteínas do leite.

\section{CONCLUSÃO}

De acordo com as análises realizadas, foi possível verificar associação do alelo B com a maior produção de Queijo minas frescal nos três grupos avaliados. Não ocorreram mudanças significativas quanto aos valores de caseína e de teores de extrato seco quando relacionado com o genótipo identificado. O conhecimento desses dados genotípicos concede um direcionamento mais adequado dos cruzamentos e a seleção prematura de animais, auxiliando substancialmente para a melhoria na produção de queijo minas frescal. 


\section{CONFLITOS DE INTERESSE}

Os autores declaram não haver qualquer potencial de conflito de interesse que possa interferir na imparcialidade deste trabalho científico.

\section{REFERÊNCIAS}

1. Alves E. Leite: o que determina os custos. Balde Branco. 1999;35(4):38-40.

2. Bressan $M$, Vilela D. Restrições técnicas, econômicas e institucionais ao desenvolvimento da cadeia produtiva de leite no Brasil: Região Centro-Oeste. Brasília: MCT/CNPq/PADCT, Juiz de Fora: Embrapa Gado de Leite, 1999. 58p.

3. Ministério da Agricultura, Pecuária e Abastecimento. Assessoria de gestão estratégica. Brasília, 2010. P.34-37.

4. Ribeiro $A B$, Guilhermino MM, Tinoco AFF. Efeito dos genótipos e da ordem de parto na qualidade do leite de vacas das raças Gir e Guzerá. V Congresso Nordestino de Produção Animal, Aracaju-SE, 2008.

5. Farrell HM, Flores RJ, Bleck GT, Brown EM, Butler JE, Creamer LK, Hicks CL, Hollar CM, NgKwai-Hang KF, Swaisgood HE. Nomenclature of the proteins of cows' milk-sixth revision. J Dairy Sci. 2004;87:1641-74. DOI: https://doi.org/10.3168/jds.S0022-

\section{2(04)73319-6}

6. Varnan AH; Sutherland JP. Leche y productos lácteos: tecnologia, química y microbiologia. Zaragoza: Acribia, AS. 1994. 476p.

7. Pinto J, Rodrigues W. Efeito do congelamento do leite de cabra obtido em diferentes estágios de lactação sobre a qualidade de queijo minas fresca. [Dissertação]. Programa de Pós-graduação em Engenharia de Alimentos da Universidade Estadual do Sudoeste da Bahia - UESB, 2012. 89p. 8. Quintana RC, Carneiro LC. Avaliação das condições higiênico-sanitárias do queijo Minas Frescal e mussarela produzidos na cidade de Morrinhos, GO. Rev Bras Saúde e Prod Animal. 2007;8(3):205-11.

9. Lima YVR. Variantes genéticas de Kappacaseína em las leiteiras características físicoquímicas e de composição do leite. [Dissertação]. Programa de Pós-Graduação em Nutrição Animal da Faculdade de Medicina Veterinária e Zootecnia da USP. 2005. 84p.

10. Van EA, Medrano JF. Milk protein polymorphisms in California dairy cattle. J Dairy Sci. 1991;74:1730-42. DOI:
https://doi.org/10.3168/ids.S0022-

0302(91)78336-7

11. Trakovická A, Moravčíková N, Navrátilová A, Kappa-casein gene polymorphism (csn3) and its effect on milk production traits. Slovak University of Agriculture in Nitra, Slovakia Acta fytotechnica et zootechnica 3 Nitra, Slovaca Universitas Agriculturae Nitriae. 2012:61-4.

12. Stipp AT, Bignardi PR, Poli-Frederic RC, Sivieri $\mathrm{K}$, Costa MR. Polimorfismos genéticos da kappacaseína e da beta-lactoglobulina e produção de leite em bovinos. Arq Bras Med Vet Zootec. 2013;65(1):275-80.

DOI:

https://doi.org/10.1590/S010209352013000100039

13. Sambrook J, Fritsch EF, Maniatis T. Molecular cloning: a laboratory manual. 3.ed. New York: Cold Spring Harbor Laboratory Press; 2001.

14. Medrano JF, Aguilar C. Genotyping of bovine kappa-casein loci follwing DNA sequence amplification. Biotechnology. 1990;8:144-6. DOI: https://doi.org/10.1038/nbt0290-144

15. Regitano LCA, Coutinho LL. Uso de marcadores moleculares na indústria animal. In: Biologia molecular aplicada à produção animal. Brasília: Embrapa; 2001. p.12-24.

16. Zenebon O, Pascuet PT. Normas Analíticas do Instituto Adolfo Lutz. 1:b Métodos químicos e físicos para análise de alimentos, 4.ed. São Paulo: Instituto Adolfo Lutz; 2008.

17. Saboya VL, Oliveira JÁ, Furtado MM, Spadoti LM. Efeitos físico-químicos da adição de leite reconstituído na fabricação de queijo minas frescal. Rev Ciênc Tecnol Aliment. 1998;18(4):368-78. DOI: http://dx.doi.org/10.1590/S010120611998000400002

18. Foschiera JL. Indústria de laticínios: Industrialização do leite, análises, produção de derivados. Porto Alegre: Suliani Editografia Ltda; 2004.

19. Deb R, Singh U, Kumar S, Singh R, Sengar G, Harma A. Genetic polymorphism and association of kappa-casein gene with milk production traits among Frieswal (HF $\times$ Sahiwal) cross breed of Indian origin. Iranian J Veter Res. 2016;15(4):4068.

20. Oner Y, Elmaci C. Milk protein polymorphisms in Holstein cattle. Int J Dairy Techn. 2006;59(3):180-2. DOI: https://doi.org/10.1111/i.14710307.2006.00259.x 
21. Jairam BT, Nair PG. Genetic variants of milk proteins in different breeds of cattle. Indian J Dairy Sci. 1983;36:5-11.

22. Ng-kwai-hang KF, Hayes JE, Moxley JD, Monardes HG. Association of genetic variants of casein and milk serum protein with milk fat and protein production in dairy cattle. J Dairy Sci. 1984;67:835-40.

DOI:

https://doi.org/10.3168/jds.S0022-

0302(84)81374-0

Recebido para publicação em 12/08/2016

Revisado em 05/09/2016

Aceito em 15/09/2016 